\title{
Acute heart failure: Can modern therapy delay or prevent death?
}

\section{Acute heart failure in sub-Saharan Africa}

Acute heart failure (AHF) is a common mechanism of death in sub-Saharan Africa (SSA). ${ }^{[1]}$ The most common cause is untreated hypertension, which as elsewhere in the world, including Europe, the USA, India, China, Africa and South Africa (SA), has a dire prognosis associated with high mortality.

The treatment of this common condition in SSA is not well documented. However, it is likely that, as in North America, loop diuretics are usually tried early in the course of therapy. In North America, patients with decompensated AHF are given loop diuretics as an essential component of therapy ${ }^{[2]}$ yet there are few randomised prospective data to guide their use. There were no significant differences in patients' global assessment of symptoms or in the change in renal function when diuretic therapy was administered by bolus as opposed to continuous infusion, or at a high dose as opposed to a low dose.

\section{Hypertension as a cause of heart failure}

Hypertension is common in Africa, as is heart failure. ${ }^{[1]}$ Establishing the cause of AHF would enable specific therapy to be started as a matter of urgency. For example, a patient with hypertensive AHF needs urgent intravenous therapy to reduce the blood pressure. Besides the typical clinical presentation of cardiomegaly and often atrial fibrillation, AHF may first manifest itself indirectly as left ventricular systolic dysfunction, especially in the elderly and in people with diabetes. ${ }^{[3]}$

Analysis of gender differences in AHF shows that modifiable lifestyle risk factors are prominent in men, while women more commonly have rheumatic heart disease and nutritional deficiencies, as shown in the Sub-Saharan Africa Survey of Heart Failure (THESUSHF) study on 1006 subjects. ${ }^{[4]}$ This study found that the causes of AHF in Africa were typically non-ischaemic, with hypertension a prominent cause. In contrast, in North America and in European countries the typical cause of AHF is ischaemic heart disease rather than hypertension. ${ }^{[5]}$

\section{Conclusion}

With regard to the treatment of AHF, there are both clinical and research messages. Neglected hypertension, although relatively easy to treat, is a frequent source of AHF. The problem in rural African communities in SSA is that hypertension is seldom diagnosed and appropriate therapy is seldom instituted, so that a crisis is likely to occur after years of neglect. Ideally, the populations of sub-Saharan countries such as Nigeria, Kenya, Tanzania, SA and Mozambique should have much better access to mobile clinics that can reach the non-urban population.

The clinical message is that not only are the complications of significant hypertension susceptible to therapy, but preventive measures such as salt reduction, mobile clinics and workplace blood pressure measurements would help to counter the disease earlier. The research message is that laboratory research should focus on preventive therapy directed at preservation of the threatened myocardium, including much wider use of angiotensin-converting enzyme inhibitors or even novel metabolic therapy such as reducing the elevated cardiotoxic blood free fatty acids.

\section{Lionel Opie, Gaurang Deshpande}

Hatter Institute for Cardiovascular Research in Africa, Department of Medicine, Faculty of Health Sciences, University of Cape Town, South Africa

Corresponding author: L Opie (lionel.opie@uct.ac.za)

1. Damasceno A, Mayosi BM, Sani M, et al. The causes, treatment, and outcome of acute heart failure in 1006 Africans from 9 countries. Arch Intern Med 2012;172(18):1386-1394. [http://dx.doi.org/10.1001/ archinternmed.2012.3310

2. Ojji D, Atherton J, Sliwa K, Alfa J, Ngabea M, Opie L. Left ventricular systolic dysfunction in asymptomatic black hypertensive subjects. Am J Hypertens 2015;28(7):924-929. [http://dx.doi org/10.1093/ajh/hpu247]

3. Ogah OS, Davison BA, Sliwa K, et al. Gender differences in clinical characteristics and outcome of acute heart failure in sub-Saharan Africa: Results of the THESUS-HF study. Clin Res Cardio 2015;104(6):481-490. [http://dx.doi.org/10.1007/s00392-015-0810-y]

4. Sliwa K, Davison BA, Mayosi BM, et al Readmission and death after an acute heart failure event: predictors and outcomes in sub-Saharan Africa: Results from the THESUS-HF registry. Eur Heart J 2013;34(40):3151-3159. [http://dx.doi.org/10.1093/eurhearti/eht393

Opie LH. Cardioprotection from metabolism to molecules to certainties. S Afr Med J 2012;102(6):491-492. 